\title{
Expression Profiling of Heat Shock Protein Genes in Two Contrasting Maize Inbred Lines
}

\author{
Krishan Kumar $^{1}$, Ishwar Singh ${ }^{1 *}$, Chetana Aggarwal $^{1}$, Ishita Tewari ${ }^{1,2}$, \\ Abhishek Kumar Jha ${ }^{1}$, Pranjal Yadava ${ }^{1}$ and Sujay Rakshit ${ }^{1}$ \\ ${ }^{1}$ ICAR-Indian Institute of Maize Research, Pusa Campus, New Delhi 110012, India \\ ${ }^{2}$ Gautam Buddha University, Greater Noida, India \\ *Corresponding author
}

\section{Keywords}

Heat shock proteins, Maize, In-silico analysis, Real-time PCR, Heat tolerance

Article Info

Accepted:

04 May 2019

Available Online:

10 June 2019

\section{A B S T R A C T}

High temperature stress is one of the most detrimental abiotic stresses which adversely affect productivity of maize (Zea mays L.) in tropics and subtropics. Plants respond to high temperature stress by regulating expression of an array of genes, heat shock proteins (HSPs) being one of them. Owing to highly differential expression of HSPs in various crop species under high temperature stress, these could be considered as key stress responsive genes. Since HSPs gene family contain various members, identification of specific gene(s) playing crucial role in heat stress tolerance could be beneficial for developing stress resilient genotypes. Here we report in-silico characterization of five HSP genes and their expression analysis in two contrasting maize inbred lines i.e. LM17 (heat tolerant) and HKI1015WG8 (heat susceptible) subjected to high temperature stress at seedling stage. The five maize specific HSP genes, viz., ZmHsp26, ZmHsp60, ZmHsp70, ZmHsp82 and ZmHsp101 exhibited distinctive expression pattern in response to heat stress. Higher upregulation of $\mathrm{ZmHsp} 70$ was found throughout the stress exposure in the heat tolerant line as compared to the susceptible line. Sharp up-regulation and rapid decline in expression of ZmHsp82 in LM17 than HKI1015WG8 after 12 hours heat stress exposure suggested its possible role in plant acclimatization to heat-stress conditions. Further, higher upregulation of ZmHsplol even after removal of stress (recovery for $24 \mathrm{hrs)} \mathrm{indicated} \mathrm{its}$ possible role in recovering plant from adverse effects of heat stress. The study opens up scope for investigation through transgenic (RNAi and/or over-expression) approach to further characterize and elucidate precise role of $\mathrm{ZmHsp101,} \mathrm{ZmHsp} 82$ and $\mathrm{ZmHsp} 70$ in heat stress tolerance in maize.

\section{Introduction}

A plethora of environmental factors referred to as abiotic stresses, viz., drought, heat, cold, flooding, salinity, etc. exert a negative impact on growth and development of crop plants, leading to significant reduction in grain yield
(Tuteja and Gill, 2013). With the everchanging climatic conditions, the impact of these abiotic stresses is expected to enhance in near future. The constantly rising ambient temperature (heat stress) is one of the most important abiotic stresses that severely affect the plant growth, development, metabolism, 
grain quality and yield in major cereal/food crops, hence becomes most remarkable global concern (Wilhelm et al., 1999; Gooding et al., 2003; Jagadish et al., 2007; Shi et al., 2017). In general, a transient increase in temperature, usually $10-15^{\circ} \mathrm{C}$ above the optimum temperature, is considered as heat stress (Wahid et al., 2007). The annual mean air temperature of nearly $23 \%$ of the land on the earth is estimated above $40^{\circ} \mathrm{C}$ (Leone et al., 2003). It is predicted that the global temperature will increase by $1.7-3.8^{\circ} \mathrm{C}$ by the end of twenty-first century (Wigley and Raper, 1992; IPCC, 2014). The climate modeling studies have anticipated the increase in day and night temperature in the future and hence expected significant reduction in the global food production (Lobell et al., 2011; Cairns et al., 2012). For instance, in 1980 and 1988 , US heat waves resulted in reduction in agricultural production with estimated loss of about 55 and 71 billion dollars, respectively (Mittler et al., 2012). Over the past three decades (1980-2008), heat stress has caused a decrease of $3.8 \%$ and $5.5 \%$ in the global yields of maize and wheat, respectively (Lobell et al., 2011). Therefore, sustaining high yield under heat stress is an utmost challenge in front of scientific community.

Heat stress mainly results in improper folding of protein which in turn leads to protein dysfunction and aggregation (Singh and Shono, 2005). The misfolding of proteins/enzymes adversely affects plant overall growth and development. To cope up with heat stress, crop plants alter their metabolism in many ways such as, by activating signalling cascades and regulatory proteins like heat shock transcriptional factors (HSFs), activating/modifying antioxidant defence system to maintain cellular homeostasis, synthesizing and accumulating compatible solutes (polyamines, sugars, proline, betains, etc) which assist in osmotic adjustment (Wahid et al., 2007; Bokszczanin and Fragkostefanakis, 2013; Hasanuzzaman et al., 2013). At the molecular level, heat stress causes alterations in expression of an array of genes encoding for osmoprotectants, ion transporters, detoxifying enzymes, transcription factors and heat shock proteins (HSPs) (Wahid et al., 2007; Qin et al., 2008; Sarkar et al., 2014; Dutra et al., 2015; Frey et al., 2015, Yadava et al., 2015). These adaptive changes in plants in response to heat stress in turn help in minimizing the adverse effect of stress on plants by maintaining the near-optimal conditions for plant growth and development (Yadava et al., 2016). Among the heat stress responsive genes, HSPs are the most frequently and quantitatively observed genes under high temperature stress condition in various crop species (reviewed by Kotak et al., 2007; Reddy et al., 2016; Mishra et al., 2018). HSPs are molecular chaperones which are involved in protein quality control, mainly by assisting proper re-folding of misfolded proteins during stress condition which in turn prevents protein aggregation hence play a crucial role in conferring heat and other abiotic stress tolerance in crops (Reddy et al., 2016; Singh et al., 2016; Mishra et al., 2018). Based on their molecular weight, HSPs have been classified into five sub-classes: HSP100, HSP90, HSP70, HSP60 and small sHSPs or low molecular weight HSPs (Wang et al., 2004, Singh and Shono, 2005). In addition to stress tolerance, members of HSP families also have their role in normal growth and development in plants.

Maize (Zea mays L.), is the second most widely grown crop in the world. In comparison to other grain crops, demand for maize would rapidly increase because of its myriad uses in various industrial products and processes and requirement for animal feed. By 2030, global maize production has to increase significantly from the current levels and that too with limited resources, shrinking arable land and a changing climate which 
anticipate increasing temperature. Maize crop is highly sensitive to drought and high temperature stress, particularly at reproductive phase, viz., flowering and early grain filling stages (Dass et al., 2010; Cairns et al., 2012). Most of the tropical maize cultivating areas in South Asia is prone to heat stress (Prasanna, 2011). The consequences of heat stress in maize are tassel blast, leaf firing, enhanced leaf senescence and reduced photosynthesis (Crafts-Brander and Salvucci, 2002; Hussain et al., 2006; Chen et al., 2010. Further, high temperature during reproductive phase reduces pollen viability (Schoper et al., 1987; Singh and Shono, 2003), silk receptivity and leads to reduced number of kernel per ear which in turn results in poor seed set and reduced grain yield (Johnson, 2000, Singh et al., 2017). It has been shown that each degree day spent above $30^{\circ} \mathrm{C}$ reduced the final maize yield by $1 \%$ and $1.7 \%$ under favorable growing and drought stress conditions respectively (Lobell et al., 2011).

In order to curtail the yield losses caused by high temperature stress in maize and to develop thermo tolerant genotypes, a better understanding of heat stress responsive key genes and master regulators such as transcription factors, playing pivotal role in tolerance mechanism is needed.

Owing to their highly altered expression during heat stress, HSPs are considered as potential candidates to address the issue of heat stress. However, not much information is available regarding the transcript profiling of HSP genes in tropical maize under high temperature stress. Therefore, in the present study, expression analysis of five HSP genes in two contrasting maize inbred lines i.e. LM17 (heat tolerant) and HKI1015WG8 (heat susceptible) subjected to high temperature stress during seedling stage was performed. The expression profiling revealed distinctive expression patterns for HSPs in response to heat stress.

\section{Materials and Methods}

\section{Plant material and growth conditions}

Maize inbred lines, HKI1015WG8 and LM17 which have been identified as heat susceptible and heat tolerant, respectively, were used in the present study (Debnath et al., 2016, Singh et al., 2017). The two inbred lines were grown under controlled condition in greenhouse at ICAR-IIMR, Pusa Campus, New Delhi. The seedlings were raised in small thermocol cups (7 $\mathrm{cm}$ top diameter) filled with a mixture of vermiculite, coco peat and soil (1:1:2). One set of two weeks old seedlings were exposed to heat stress $\left(42^{\circ} \mathrm{C}\right)$ for different intervals of time (3, 6, 9 and 12 hours) while other set was kept at $25^{\circ} \mathrm{C}$ in plant growth chambers. The leaf samples from both the sets were collected at each time-point (3, 6, 9, 12 hours) and after recovery for $24 \mathrm{hrs}$ ( $24 \mathrm{hrs}$ recovery by growing at $25^{\circ} \mathrm{C}$ after $12 \mathrm{hrs}$ heat exposure). The collected leaf samples were immediately frozen in liquid nitrogen and stored at $-80^{\circ} \mathrm{C}$ until used for total RNA extraction.

\section{RNA isolation}

Total RNA was isolated from the leaf samples using Ambion Pure Link ${ }^{\mathrm{TM}}$ Plant RNA kit (Invitrogen) according to the manufacturer's protocol. The quality and concentration of the isolated RNA was assessed by Nano Drop spectrophotometer (Nano 200) and the integrity of the RNA was also verified on gel electrophoresis. The RNA was stored at -80 ${ }^{\circ} \mathrm{C}$.

\section{Quantitative real-time PCR (qRT-PCR) analysis}

First strand cDNA was synthesized using $1 \mu \mathrm{g}$ of total RNA using Affinity Script qRT-PCR 
cDNA synthesis kit (Agilent Technologies, USA) according to the manufacturer's instructions. Maize Hsp gene sequences were obtained from NCBI and gene specific qRTPCR primers (Table 1) were designed using Primer Quest software (http://eu.idtdna.com).

The qRT-PCR was performed in triplicate using the Brilliant-III Ultra-fast SYBR Green master mix in AriaMx real-time PCR (Agilent Technologies, USA) detection system. The Actin gene was used as reference gene to normalize the expression values. The expression level in leaf tissue from unstressed/control plants was selected as calibrator.

The fold change value ( $\log _{2}$ scale) for mRNA expression level compared/relative to expression in control plants (grown at $25^{\circ} \mathrm{C}$ ) was calculated using comparative $\Delta \Delta \mathrm{C}_{\mathrm{t}}$ method (Livak et al., 2001). In this method the fold change $=2^{-\Delta \Delta \mathrm{Ct}}$, where $\Delta \Delta \mathrm{C}_{\mathrm{t}}=\left(\mathrm{C}_{\mathrm{t}}\right.$ (gene of interest) $\left.-C_{t \text { (actin) }}\right)$ test $-\left(C_{t}\right.$ (gene of interest) $-C_{t}$ (actin) control/calibrator

\section{In-silico analysis of $\mathrm{Hsp}$ genes}

The theoretical $\mathrm{pI}$ (isoelectric point) and $\mathrm{Mw}$ (molecular weight) of HSP proteins were predicted by Expasy-Computer $\mathrm{pI} / \mathrm{Mw}$ tool (http://www.expasy.org). The WoLF PSORT program (https://wolfpsort.hgc.jp/) was used to predict the sub-cellular localization of ZmHSPs.

The amino acid sequences were further used for predicting the domain architecture using Inter Pro (http://www.ebi.ac.uk/interpro) and Simple Modular Architecture Research Tool (SMART) (http://smart.embl-heidelberg.de/). Further, signature sequence unique to any protein family was identified using PROSITE tool (https://prosite.expasy.org/cgi-bin/prosite/ PSScan.cgi).

\section{Results and Discussion}

\section{Identification and in-silico characterization of $\mathrm{ZmHsp}$ genes}

Five heat shock protein encoding genes belonging to different families were retrieved from the maize genome database (https://www.maizegdb.org/gene_center/gene) and their respective amino acid sequences were retrieved from NCBI. The amino acid sequences were analyzed by different bioinformatics software used to predict molecular weight, isoelectric point (pI) and sub-cellular localization, enlisted in Table 2. On the basis of molecular weight, these Hsps were grouped into different families (Table 2).

The unique signature sequence prediction by PROSITE tool confirmed the respective family of these five $H s p$ genes. Protein domain analysis predicted the domain architecture of five HSP proteins as enlisted in Table 3. The low complexity regions (LCRs), repetitive sequences or sequences enriched in one/few aminoacids, were predicted in all five HSPs (Figure 1 and Table $3)$. These LCRs have been reported in extreme abundance in eukaryotic proteins (Golding 1999; Marcotte et al., 1999). The LCRs have shown to contribute to variability/diversity across protein families and involved in protein-protein and proteinnucleic acid interactions modulation (Xiao and Jeang 1998; Shen et al., 2004). In ZmHsp82 and ZmHspl01, adenosine triphosphate (ATP) binding domain which binds to and hydrolyzes ATP, viz., HATPase_c and AAA, respectively were predicted (Figure 1 and Table 3 ). In general, HSPs derive energy from ATP hydrolysis for molecular chaperone activities (remodeling or disaggregation of protein aggregates) (Burton and Baker, 2005; reviewed by Sable and Agarwal, 2018). 
Expression analysis of $\mathrm{ZmHsp}$ genes at seedling stage

The qRT-PCR based expression analysis of identified $Z m H s p$ genes was performed in contrasting maize inbred lines at different time-points after heat stress exposure $(3,6,9$ and 12 hours) and after recovery. The increased expression / up-regulation of all five $H s p s$ were observed at various time intervals after heat stress treatment in both the lines with respect to their respective control (non-stressed) plants, which suggested that heat stress induced the expression of all $5 \mathrm{Hsp}$ genes investigated in this study (Figure 2). However, the level of up-regulation varied at different time-points in the contrasting lines. Out of five Hsps, up-regulation of two Hsps (ZmHsp26 and ZmHsp60) was higher in susceptible genotype compared to the tolerant one. The expression of ZmHsp26 increased rapidly in susceptible genotype after 6 hours of heat exposure but lacked any specific pattern. Expression of $\mathrm{ZmHsp} 60$ was higher in susceptible genotype at all the time-points than in the tolerant one. The greater upregulation in susceptible line suggested that these two Hsps genes might be playing role in normal cellular growth/development/ maintenance and not be crucial for imparting heat stress tolerance in tropical maize. The level of up-regulation for remaining three Hsps (ZmHsp70, ZmHsp82 and ZmHsp101) was significantly higher in tolerant line compared to the susceptible line (Figure 2). Previously, it has been shown that Hspl0O and $H s p 90$ work in association with $H s p 70$ and constitute chaperone complexes, which in turn evaded protein aggregation under stress condition (Reddy et al., 2016; Mishra et al., 2018). Further, Hsp 90 and $H s p 70$ and their co-chaperones (sHSPs) had shown to interact with various components of signalling molecules like hormone receptors, tyrosine/ threonine/ serine-kinase receptors and resulted into acquired tolerance (Wang et al.,
2004). Therefore, these three Hsps (ZmHsp70, ZmHsp82 and ZmHsp101) might be crucial for imparting thermotolerance and sufficient up-regulation of them required for the same. In our study, higher up-regulation of these three Hsps was observed in tolerant genotype than in the susceptible genotype.

The higher up-regulation of ZmHsp82 (HSP90 family member) and ZmHsp101 (HSP100 family member) was detected in LM17 (heat tolerant) than HKI1015WG8 (heat susceptible) after 12 hours stress treatment and after recovery, respectively. In case of ZmHsp82, rapid and very sharp upregulation was observed after 12 hours of heat exposure while very less transcript level was found after recovery. The up-regulation in tolerant line was almost twice than upregulation in susceptible line after 12 hours of heat stress treatment. This transient induction in expression suggested that higher expression of ZmHsp82 was required at much later timepoint during heat stress exposure to acclimatize plants to heat stress and basal level or very minimal expression is required under normal conditions. In Arabidopsis, HSP90 has been shown to regulate the heat shock response that is responsible for heat acclimation (Yamada et al., 2007). HSP90 in association with HSP70, constituted a major part of chaperone complexes and helped in protein folding. Similarly, several other studies had also shown up-regulation of Hsp90 under high temperature stress (Majoul et al., 2004; Hu et al., 2009; Li et al., 2013).

In case of ZmHsp101 transcript level started increasing with the onset of high temperature stress in both the lines. However the upregulation was significantly higher (more than 2.5 fold) in the tolerant line than the susceptible line after 24 hours of recovery. The study suggested that higher expression of ZmHsp101which sustained even after stress is removed might play a major role for heat 
stress acclimation of the maize plant. Previous studies have shown that disaggregating chaperone, HSP100, promoted protein disaggregation under heat stress condition hence required for both basal and acquired thermotolerance (Parsell et al., 1994; Glover and Lindquist, 1998; Quietsch et al., 2000: reviewed by Mittler et al., 2012). It has been reported essential for acquisition of high temperature tolerance in yeast (known as Hsp104), and plants (known as HsplO1) such as soybean, Arabidopsis, tobacco and wheat (Sanchez and Lindquist, 1990; Lee et al., 1994; Schirmer et al., 1994; Wells et al., 1998; Hong and Vierling, 2000). Further, over expression of HsplO1 gene in Arabidopsis (Quietsch et al., 2000) and rice (KatiyarAgarwal et al., 2003) exhibited high temperature tolerance in transgenic plants. Our studies also suggested higher expression of $\mathrm{ZmHsp101} \mathrm{even} \mathrm{after} \mathrm{stress} \mathrm{removal} \mathrm{could}$ be responsible for conferring thermotolerance in maize.

The expression level of ZmHsp70, was higher in tolerant line than susceptible one subjected to heat stress for 3 to 12 hours. Further, shifting the plants to normal temperature conditions for 24 hours after 12 hours of heat treatment resulted into significant reduction in its expression in the tolerant line only. $H s p 70$, has been reported to promote refolding of denatured proteins once released from the protein aggregates (reviewed by Parsell and Lindquist, 1993; Miernyk, 1999). Over expression of $H s p 70$ in Arabidopsis, tobacco and rice has been proven useful in imparting thermotolerance by suppressing programmed cell death and preventing fragmentation and degradation of genomic DNA during heat stress (Cho and Choi, 2009: MonteroBarrientos et al., 2010; Qi et al., 2011). Recent studies in rice (Sarkar et al., 2013) and tea plant (Chen et al., 2018) have also shown induced expression of $\mathrm{Hsp} 70$ under heat stress. Higher expression of $\mathrm{Hsp} 70$ in tolerant line in our study showed strong correlation between transcript level and thermotolerance. The three highly expressed Hsps ( $\mathrm{ZmHsp} 70$, ZmHsp82 and ZmHsp101) in LM 17, a heat tolerant maize inbred line, could play a crucial role in conferring heat tolerance by refolding of misfolded proteins during stress and need to be further investigated more comprehensively.

Table.1 List of primers used for qRT-PCR analysis

\begin{tabular}{|c|c|c|c|}
\hline S. No. & Gene name & Primer Sequence ( $\left.5^{\prime}->3^{\prime}\right)$ & $\operatorname{Tm}\left[{ }^{\circ} \mathbf{C}\right]$ \\
\hline \multirow{2}{*}{. 170} & \multirow[b]{2}{*}{ Hsp101 } & F- ACCGCAAGTACGTGGAGAAG & 59.4 \\
\hline & & R- GTACCTCGCGCATAGCTGTG & 61.4 \\
\hline \multirow[b]{2}{*}{2} & \multirow[b]{2}{*}{ Hsp 26} & F- CGACGTACAGGTTAGCCAGA & 59.4 \\
\hline & & R- GTCCATCGTGTCCAGCATCT & 59.4 \\
\hline \multirow[b]{2}{*}{3} & \multirow[b]{2}{*}{ Hsp82 } & F- ACGCTGTCCATCATCGACTC & 59.4 \\
\hline & & R- GTGGTGACCATGACCCTGTC & 61.4 \\
\hline \multirow[b]{2}{*}{4} & \multirow[b]{2}{*}{ Hsp60 } & F- CCTTACCGGAGGAGAGGTAATA & 60.3 \\
\hline & & R- CTCCAGCGCCATCAAGAATA & 57.3 \\
\hline \multirow[b]{2}{*}{5} & \multirow[b]{2}{*}{ Hsp70 } & F- AAGTAAGGAGGAGATCGAGAAGA & 58.9 \\
\hline & & R- CTGATGGTGTTGCGCATATTG & 57.9 \\
\hline \multirow[b]{2}{*}{6} & \multirow[b]{2}{*}{ Actin } & F- CAATGGCACTGGAATGGT & 53.7 \\
\hline & & R- ATCTTCAGGCGAAACACG & 53.7 \\
\hline
\end{tabular}


Table.2 Characteristics of the five $Z m H S P$ proteins in maize

\begin{tabular}{|c|c|c|c|c|c|}
\hline Gene Name & $\begin{array}{l}\text { Accession } \\
\text { Number }\end{array}$ & $\begin{array}{l}\text { Molecular } \\
\text { weight } \\
\text { (Dalton) }\end{array}$ & $\begin{array}{l}\text { Isolectric } \\
\text { Point (pI) }\end{array}$ & $\begin{array}{c}\text { Family } \\
\text { name }\end{array}$ & $\begin{array}{l}\text { *Subcellular } \\
\text { Localization }\end{array}$ \\
\hline ZmHsp26 & NP_001105583.1 & 26377.94 & 7.86 & sHSP & chlo: 13 , nucl: 1 \\
\hline ZmHsp60 & NP_001105690.1 & 60935.09 & 5.67 & HSP60 & mito: 12 , chlo: 2 \\
\hline ZmHsp70 & NP_001148198.1 & 71138.34 & 5.05 & HSP70 & $\begin{array}{c}\text { cyto: } 9 \text {, cysk: } 4 \text {, } \\
\text { chlo: } 1\end{array}$ \\
\hline ZmHsp82 & NP_001135416.3 & 81802.65 & 5.03 & HSP90 & $\begin{array}{l}\text { cyto: } 7 \text {, E.R.: 3, } \\
\text { nucl: } 1 \text {, plas: } 1 \text {, } \\
\text { vacu: } 1 \text {, golg: } 1\end{array}$ \\
\hline ZmHsp101 & NP_001104935.2 & 101118.68 & 5.84 & HSP100 & $\begin{array}{c}\text { cyto: } 4 \text {, nucl: } 2 \text {, } \\
\text { vacu: } 2 \text {, E.R.: } 2 \text {, } \\
\text { pero: } 2 \text {, mito: } 1 \text {, } \\
\text { plas: } 1\end{array}$ \\
\hline
\end{tabular}

*Chlo: chloroplast, cyto: cytoplasm, ER: endoplasmic reticulum, golg: golgi apparatus, mito: mitochondria, nucl: nucleus, pero: peroxide, plas: plasma membrane, vacu: vacuole, cysk: cytoskeleton

Table.3 Unique signature sequence and domain architecture of the five ZmHSP proteins in maize

\begin{tabular}{|c|c|c|c|c|}
\hline $\begin{array}{l}\text { Gene } \\
\text { Name }\end{array}$ & $\begin{array}{l}\text { Predicted unique } \\
\text { signature sequence }\end{array}$ & $\begin{array}{l}\text { Amino acid } \\
\text { positions of } \\
\text { predicted } \\
\text { sequence }\end{array}$ & $\begin{array}{c}\text { Protein family to } \\
\text { which signature } \\
\text { belongs }\end{array}$ & $\begin{array}{l}\text { *Predicted } \\
\text { domain }\end{array}$ \\
\hline ZmHsp26 & sHSP domain & $124-240$ & sHSP family & $\begin{array}{c}\text { low } \\
\text { complexity }\end{array}$ \\
\hline ZmHsp60 & AAVEEGIVpGGG & $438-449$ & $\begin{array}{c}\text { Chaperonins cpn60 } \\
\text { (HSP60) family }\end{array}$ & $\begin{array}{l}\text { low complexity, } \\
\text { coiled coil }\end{array}$ \\
\hline ZmHsp70 & $\begin{array}{c}\text { IDLGTTyS, } \\
\text { IFDLGGGTfdvSLL } \\
\& \\
\text { VvLvGGsTRIPrVq } \\
\text { Q }\end{array}$ & $\begin{array}{c}12-19 \\
203-216 \\
\& \\
340-354\end{array}$ & HSP70 family & $\begin{array}{c}\text { low } \\
\text { complexity, } \\
\text { coiled coil }\end{array}$ \\
\hline ZmHsp82 & YsNKEIFLRE & $35-44$ & HSP90 family & $\begin{array}{l}\text { HATPase_c, coiled } \\
\text { coil, low complexity }\end{array}$ \\
\hline ZmHsp101 & $\begin{array}{c}\text { DAANLFKPmLarG } \\
\& \\
\text { RIDmSEYmEQhSv } \\
\text { A-RLiGA }\end{array}$ & $\begin{array}{c}297-309 \\
\& \\
633-651\end{array}$ & $\begin{array}{c}\text { Chaperonins clpA/B } \\
\text { (HSP 100) family }\end{array}$ & $\begin{array}{c}\text { low } \\
\text { complexity, } \\
\text { AAA, coiled } \\
\text { coil, } \\
\text { ClpB_D2- } \\
\text { small }\end{array}$ \\
\hline
\end{tabular}

* HATPase_C: Histidine kinase-like ATPases, AAA: ATPases associated with a variety of cellular activities, ClpB_D2-small: C-terminal, D2-small domain, of ClpB protein 
Fig.1 Distribution of protein domains in selected ZmHSPs. HATPase_C: Histidine kinase-like ATPases, AAA: ATPases associated with a variety of cellular activities, ClpB_D2-small: Cterminal, D2-small domain, of ClpB protein. Low complexity region and Coiled-coil region represented by pink and green color respectively
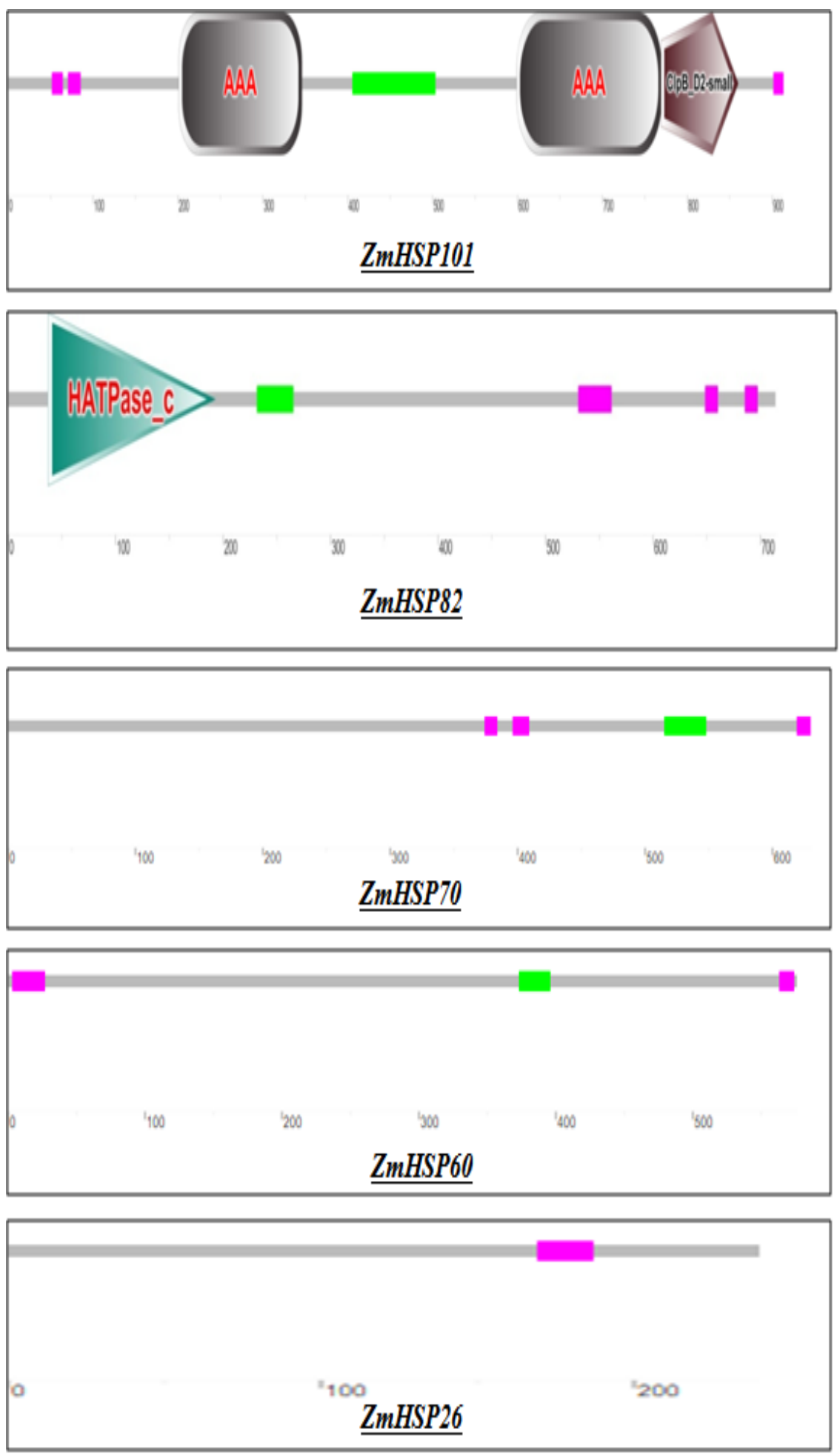
Fig.2 (A-E) Expression analysis of ZmHsp genes in LM17 (represented by green colour) and HKI1015WG8 (represented by red colour) maize inbreds in response to heat stress treatments. Values on $X$-axis represents heat stress treatment in hours while rec denotes $24 \mathrm{hrs}$ recovery by growing at $25^{\circ} \mathrm{C}$ after $12 \mathrm{hrs}$ heat exposure and $Y$-axis represents the $\log 2$ fold change in expression level in in response to heat stress treatment $\left(42^{\circ} \mathrm{C}\right)$ compared to respective control $\left(25^{\circ} \mathrm{C}\right)$. Error bars show standard deviation
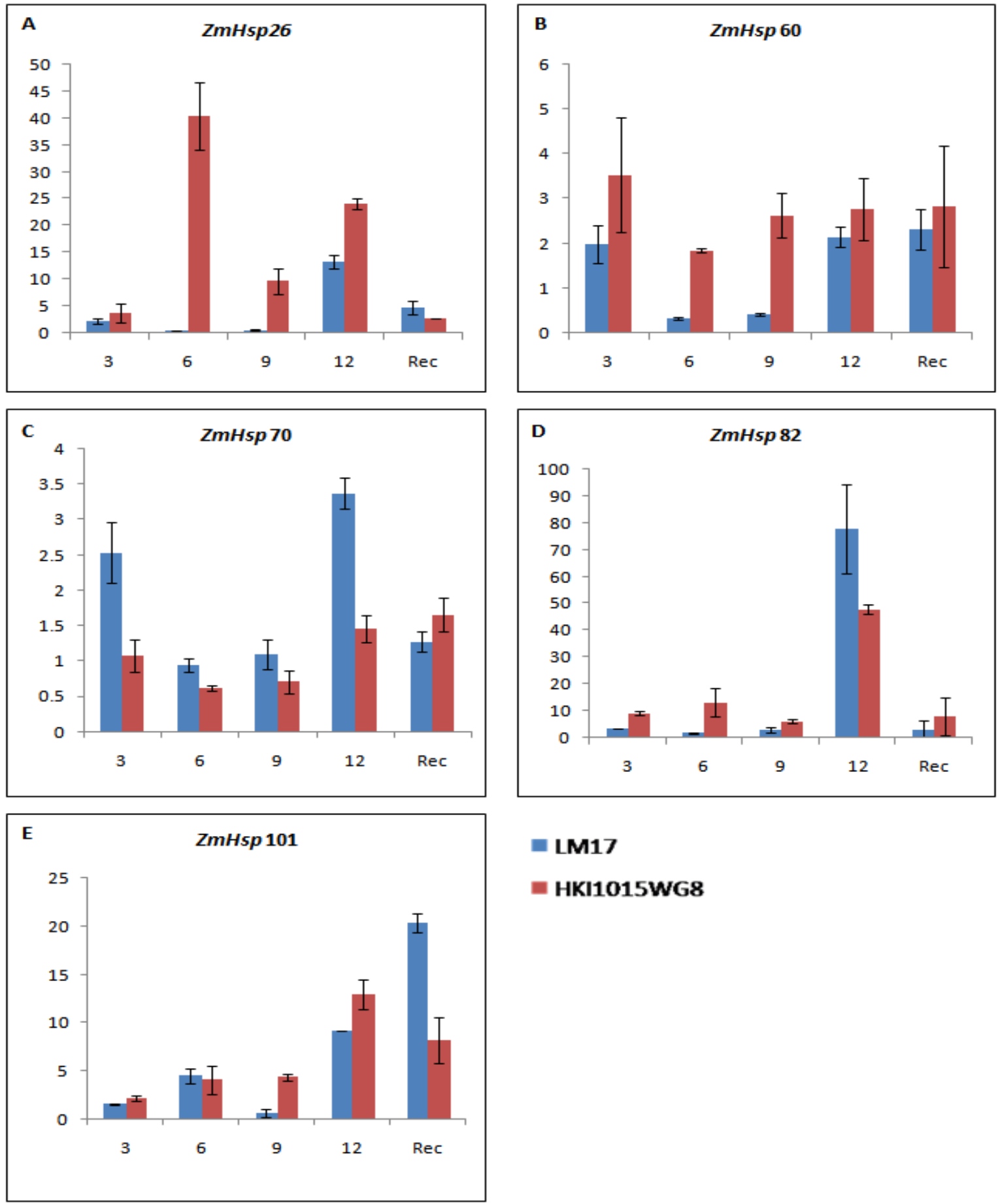

- LM17

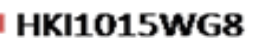


In conclusion, identifying key heat stress responsive gene(s), playing crucial role in stress adaptation to plants, is important to engineer plants for heat stress tolerance which in turn would result into sustainable yield in the era of climate change and global warming. Thus, it is essential to understand the mechanisms by which plants react and adapt to heat stress. An array of genes like HSPs is known to be induced in plants under heat stress and play a fundamental role in cellular homeostasis during stress conditions. In this study, in-silico analysis of five heat responsive HSP genes were performed and expression of these genes in two contrasting tropical maize inbred lines i.e. LM17 (heat tolerant) and HKI1015WG8 (heat susceptible) subjected to high temperature stress were carried out at seedling stage under controlled conditions. Out of five, three highly expressed Hsps (ZmHsp70, ZmHsp82 and ZmHsp101) in LM 17, a heat tolerant maize inbred line, were identified which might be playing a crucial role in conferring heat tolerance. However, role of these Hsps in heat stress adaptation needs to be further investigated more comprehensively through overexpression and/or RNAi strategies.

\section{Acknowledgement}

The authors are thankful to the Director, ICARIIMR for providing necessary facilities to carry out this work under in-house project "Physiological and molecular basis of heat tolerance in maize". The research was supported in part by funds from the National Agricultural Science Fund.

\section{Author contribution}

IS and PY conceived and planned the experiments, which were carried out by CA, IT and AKJ. KK supervised the bioinformatic and molecular experiments, analyzed the collected data and wrote the primary draft of the manuscript. SR, IS and PY provided specific comments and improved the draft. All the authors read, commented and approved the final manuscript.

\section{Conflict of interest}

The authors declare that there is no conflict of interest regarding the publication of this article.

\section{References}

Bokszczanin, K.L., and Fragkostefanakis, S. 2013. Perspectives on deciphering mechanisms underlying plant heat stress response and thermotolerance. Frontiers in Plant Science. 4: 315-335.

Burton, B.M., and Baker, T.A. 2005. Remodeling protein complexes: insights from the AAA+ unfoldase ClpX and $\mathrm{Mu}$ transposase. Protein science. 14: 1945-1954.

Cairns, J.E., Sonder, K., Zaidi, P.H., Verhulst, N., Mahuku, G., Babu, R., Nair, S.K., Das, B., Govaerts, B., Vinayan, M.T., Rashid, Z., Noor, J.J., Devi, P., Vicente, F.S., and Prasanna, B.M. 2012. Maize production in a changing climate: impacts, adaptation, and mitigation strategies. Advances Agronomy. 114: 1-65.

Chen, K.M., Holmström, M., Raksajit, W., Suorsa M, Piippo, M. and Aro, E.M. 2010. Small chloroplasttargeted DnaJ proteins are involved in optimization of photosynthetic reactions in Arabidopsis thaliana. BMC plant biology 10: 43.

Chen, J., Gao, T., Wan, S., Zhang, Y., Yang, J., Yu, Y., and Wang, W. 2018. Genome-Wide Identification, Classification and Expression Analysis of the HSP Gene Superfamily in Tea Plant (Camellia sinensis). International Journal of Molecular Sciences. 19: 2633.

Cho, E.V., and Choi, Y.J. 2009. A nuclear-localized HSP70 confers thermoprotective activity and drought-stress tolerance on plants, Biotechnology Letters. 31: 597-606.

Crafts-Brander, S.J., and Salvucci, M.E. 2002. Sensitivity of photosynthesis in a $\mathrm{C} 4$ plant, maize, to heat stress. Plant Physiology. 129: 1773-1780.

Dass, S., Singh, I., Chikkappa, G.K., Parihar, C.M., Kaul, J., Singode, A., Manivannan, A., and Singh, D.K. 2010. Abiotic Stresses in Maize: Some Issues and Solutions. Directorate of Maize Research, Indian Council of Agricultural Research, PusaCampus, New Delhi. pp. 110012.

Debnath, S., Gazal, A., Yadava, P., and Singh, I. 2016. Identification of contrasting genotypes under heat stress in maize (Zea mays L.). Maize Journal. 5: 1424.

Dutra, S.M.F., Von Pinho, E.V.R., Santos, H.O., Lima, A.C., Von Pinho, R.G., and Carvalho, M.L.M. 2015. Genes related to high temperature tolerance during maize seed germination. Genetics and Molecular Research. 14: 18047-18058.

Frey, F.P., Urbany, C., Huettel, B., Reinhardt, R., and Stich, B. 2015. Genome-wide expression profiling and phenotypic evaluation of European maize inbreds at seedling stage in response to heat stress. BMC Genomics. 16: 123.

Glover, J.R., and Lindquist, S. 1998. Hsp104, Hsp70, and Hsp40: a novel chaperone system that rescues previously aggregated proteins. Cell. 94: 73-82.

Golding, G.B. 1999. Simple sequence is abundant in 
eukaryotic proteins Protein Science. 8: 1358-1361.

Gooding, M.J., Ellis, R.H., Shewry, P.R., and Schofield, J.D. 2003. Effects of restricted water availability and increased temperature on the grain filling, drying and quality of winter wheat. Journal of Cereal Science. 37: 295-309.

Hasanuzzaman, M., Nahar, K., Alam, M.M., Roychowdhury, R., and Fujita, M. 2013. Physiological, Biochemical, and Molecular Mechanisms of Heat Stress Tolerance in Plants. International Journal of Molecular Sciences. 14: 9643-9684.

Hong, .SW., and Vierling, E. 2000. Mutants of Arabidopsis thaliana defective in the acquisition of tolerance to high temperature stress. Proceedings of the National Academy of Sciences of the United States of America. 97: 4392-4397.

$\mathrm{Hu}, \mathrm{W} ., \mathrm{Hu}, \mathrm{G}$. , and Han, B. 2009. Genome-wide survey and expression profiling of heat shock proteins and heat shock factors revealed overlapped and stress specific response under abiotic stresses in rice. Plant Science. 176: 583-590.

Hussain, T., Khan, I. A., Malik, M. A., and Ali Z. 2006. Breeding potential for high temperature tolerance in corn (Zea mays L.). Pakistan Journal of Botany. 38: 1185 .

IPCC (2014). Climate change 2014: synthesis report, in Contribution of Working Groups I, II and III to the Fifth Assessment Report of the Intergovernmental Panel on Climate Change, eds R. K. Pachauri and L. A. Meyer (Geneva: IPCC).

Jagadish, S.V.K., Craufurd, P.Q., and Wheeler, T.R. 2007. High temperature stress and spikelet fertility in rice (Oryza sativa L.). Journal of Experimental Botany. 58: 1627-1635.

Johnson, C. 2000. Ag answers: post-pollination period critical to maize yields, Agricultural Communication Service, Purdue University. p. 42.

Katiyar-Agarwal, S., Agarwal, M., and Grover, A. 2003. Heat tolerant basmati rice engineered by overexpression of hsp101. Plant Molecular Biolology. 51: 677-686.

Kotak, S., Larkindale, J., Lee, U., Von Koskull-Döring, P., Vierling, E., and Scharf, K.D. 2007. Complexity of the heat stress response in plants. Current Opinion in Plant Biology. 10: 310-316.

Lee, Y-R.J., Nagao, R.T., Key, J.L. 1994. A soybean 101 $\mathrm{kD}$ heat shock protein complements a yeast HSP104 deletion mutant in acquiring thermotolerance. Plant Cell. 6: 1889-1897.

Li, W., Wei, Z., Qiao, Z., Wu, Z., Cheng, L., and Wang, Y. 2013. Proteomics analysis of alfalfa response to heat stress. PLoS One 8: e82725.

Livak, K. J., and Schmittgen, T. D. 2001. Analysis of relative gene expression data using real-time quantitative PCR and the 2- $\Delta \Delta \mathrm{CT}$ method. Methods. 25: 402-408.

Lobell, D.B., Schlenker, W., and Costa-Roberts, J. 2011. Climate trends and global crop production since
1980. Science. 333: 616-620.

Majoul, T., Bancel, E., Triboï, E., Ben Hamida, J., and Branlard, G. 2004. Proteomic analysis of the effect of heat stress on hexaploid wheat grain: Characterization of heat-responsive proteins from non-prolamins fraction. Proteomics. 4: 505-513.

Marcotte, E.M., Pellegrini, M., Yeates, T.O., and Eisenberg, D. 1999. A census of protein repeats. Journal of Molecular Biology. 293: 151-160.

Miernyk, J.A. 1999. Protein folding in the plant cell. Plant Physiology. 121: 695-703.

Mishra, D., Shekhar, S., Singh, D., Chakraborty, S., and Chakraborty, N. 2018. Heat Shock Proteins and Abiotic Stress Tolerance in Plants. Heat Shock Proteins. 41-69.

Mittler, R., Finka, A., and Goloubinoff, P. 2012. How do plants feel the heat? Trends in Biochemical Sciences. 37: 118-125.

Montero-Barrientos, M., Hermosa, R., Cardoza, R.E., Gutiérrez, S., Nicolás, C., and Monte, E.M. 2010. Transgenic expression of the Trichoderma harzianum hsp70 gene increases Arabidopsis resistance to heat and other abiotic stresses. Journal of Plant Physiology. 167: 659-665.

Parsell, D.A., Kowal, A.S., Singer, M.A., and Lindquist, S. 1994. Protein disaggregation mediated by heatchock protein Hsp104. Nature. 372: 475-478.

Parsell, P. A., and Lindquist, S. 1993. The function of heat-shock proteins in stress tolerance: Degradation and reactivation of damaged proteins. Annual Review of Genetics. 27: 437-496.

Prasanna, B.M. 2011. Maize in Asia-trends, challenges and opportunites. In: Addressing Climate Change Effects and Meeting Maize Demand for Asia- Book of Extended Summaries of the 11th Asian Maize Conference, 7-11 November2011, CIMMYT: Mexico, DF, Nanning, China. pp. 3-6.

Qi, Y., Wang, H., Zou, Y., Liu, C., Liu, Y., Wang, Y., and Zhang, W. 2011. Over-expression of mitochondrial heat shock protein 70 suppresses programmed cell death in rice. FEBS Letters. 585: 231-239.

Qin, D., Wu, H., Peng, H., Yao, Y., Ni, Z., and Li, Z., et al. 2008. Heat stress responsive transcriptome analysis in heat susceptible and tolerant wheat (Triticum aestivum L.) by using wheat genome array. BMC Genomics. 9:432.

Queitsch, C., Hong S. W., Vierling E., and Lindquist, S. 2000. Heat shock protein 101 plays a crucial role in thermotolerance in Arabidopsis. The Plant Cell. 12: 479-492.

Reddy, P. S., Chakradhar, T., Reddy, R. A., Nitnavare, R. B., Mahanty, S., and Reddy, M.K. 2016. Role of Heat Shock Proteins in Improving Heat Stress Tolerance in Crop Plants. Heat Shock Proteins. 283307.

Sable, A., and Agarwal, S. 2018. Plant Heat Shock Protein Families: Essential Machinery for Development and Defense. Journal of Biological Sciences and Medicine. 4(1): 51-64. 
Sarkar, N.K., Kim, Y.K., and Grover, A. 2014. Coexpression network analysis associated with call of rice seedlings for encountering heat stress. Plant Molecular Biology. 84: 125-143.

Sarkar, N.K., Kundnani, P., and Grover, A. 2013. Functional analysis of Hsp70 superfamily proteins of rice (Oryza sativa). Cell Stress Chaperon. 18: 427-437.

Sanchez, Y., and Lindquist, S. 1990. HSP104 required for induced thermotolerance. Science. 248: 1112-1115.

Schirmer, E.C., Lindquist, S., and Vierling, E. 1994. An Arabidopsis heat shock protein complements a thermotolerance defect in yeast. Plant Cell. 6: 18991909.

Schoper, J.B., Lambert, R.J., and Vasilas, B.L. 1987. Pollen viability, pollen shedding and combining ability for tassel heat tolerance in maize. Crop Science. 27: 27-31.

Shen, H., and Kan, J.L., Green, M.R. 2004. Arginineserine-rich domains bound at splicing enhancers contact the branchpoint to promote prespliceosome assembly. Molecular Cell. 13: 367-376.

Shi, W., Yin, X., Struik, P.C., Solis C., Xie, F., Schmidt, R.C., Huang, M., Zou, Y., Ye, C., and Jagadish, S.V.K. 2017. High day- and night-time temperatures affect grain growth dynamics in contrasting rice genotypes. Journal of Experimental Botany. 68: 5233-5245.

Singh, I. and Shono, M. 2003. Effect of 24-epibrassinolide on pollen viability during heat-stress in tomato. Indian Journal of Experimental Biology. 41: 174176.

Singh, I. and Shono, M. 2005. Physiological and molecular effects of 24-epibrassinolide, a brassinosteroid on thermotolerance of tomato. Plant Growth Regulation. 47(2-3): 111-119.

Singh, I., Chikkappa, G.K., Atkare, A.P., Shukla, P.K., Avni, and Yadava, P. 2017. Identification of heatstress tolerant recombinant inbred lines in maize (Zea mays L.). Maize Journal. 6: 9-21.

Singh, M., Chakraborti, D., Dass, S., Singh, D.K., Singh, N., and Singh, I. 2017. Effect of high temperature and low moisture stress on morpho-physiological and biochemical characters and yield of maize hybrids. Annals of Plant and Soil Research. 19(1): 71-74.
Singh, R.K., Jaishankar, J., Muthamilarasan, M., Shweta, S., Dangi, A., and Prasad, M. 2016. Genome-wide analysis of heat shock proteins in $\mathrm{C} 4$ model, foxtail millet identifies potential candidates for crop improvement under abiotic stress. Scientific Reports. 6: 32641.

Tuteja, N., and Gill, S.S. 2016. Abiotic stress response in plants. John Wiley \& Sons.

Wahid, A., Gelani, S., Ashraf, M. and Foolad, M.R. 2007. Heat tolerance in plants: An overview. Elsevier. 61: 199-223.

Wang, W.X., Vinocur, B., Shoseyov, O., and Altman, A. 2004. Role of plant heat-shock proteins and molecular chaperones in the abiotic stress response. Trends in Plant Science. 9: 244-252.

Wells, D.R., Tanguay, R.L., Le, H., and Gallie, D.R. 1998. HSP101 functions as a specific translational regulatory protein whose activity is regulated by nutrient status. Genes and Development. 12: 32363251.

Wilhelm, E.P., Mullen, R.E., Keeling, P.L., and Singletary, G.W. 1999. Heat stress during grain filling in maize: effects on kernel growth and metabolism. Crop Science. 39: 1733-1741.

Xiao, H., and Jeang, K.T. 1998. Glutamine-rich domains activate transcription in yeast Saccharomyces cerevisiae. Journal of Biological Chemistry. 273: 22873-22876.

Yadava, P., Kaushal, J., Gautam, A., Parmar, H., and Singh, I. 2016. Physiological and Biochemical Effects of 24-Epibrassinolide on Heat-Stress Adaptation in Maize (Zea mays L.). Natural Science. 8: 171-179.

http://dx.doi.org/10.4236/ns.2016.84020.

Yadava, P., Nepolean, T., Kaur, P., Kaliyugam, S., and Singh, I. 2015. Salicylic acid alleviates methyl viologen induced oxidative stress through transcriptional modulation of antioxidant genes in Zea mays L. Maydica. 60: M21.

Yamada, K., Fukao, Y., Hayashi, M., Fukazawa, M., Suzuki, I., and Nishimura, M. 2007. Cytosolic HSP90 regulates the heat shock response that is responsible for heat acclimation in Arabidopsis thaliana. Journal of Biological Chemistry. 282(52): 37794-804.

\section{How to cite this article:}

Krishan Kumar, Ishwar Singh, Chetana Aggarwal, Ishita Tewari, Abhishek Kumar Jha, Pranjal Yadava and Sujay Rakshit. 2019. Expression Profiling of Heat Shock Protein Genes in Two Contrasting Maize Inbred Lines. Int.J.Curr.Microbiol.App.Sci. 8(06): 347-358.

doi: https://doi.org/10.20546/ijcmas.2019.806.039 